\title{
Do direito à profissionalização e da proteção no trabalho ao adolescente à luz do estatuto da criança e do adolescente
}

\author{
Douglas Henrique de Oliveira ${ }^{1}$ \\ Vilma Aparecida do Amaral ${ }^{2}$
}

\begin{abstract}
Resumo
Busca-se compreender como se configura o tratamento dado ao trabalho do adolescente pela nossa legislação, bem como refletir sobre a finalidade de sua proteção. No Brasil, segundo dados do ano de 2006 do IBGE, conforme mencionado no presente trabalho, mais de cinco milhões de crianças e adolescentes trabalham e muitas delas de modo ilegal. É diante dessa realidade que o tratamento legal deve ser observado e não como um empecilho ao trabalho, já que este, dentro de limites e conjugado com a educação, contribui para a formação do indivíduo.
\end{abstract}

Palavras-Chave: Trabalho; Profissionalização; Adolescente; Proteção; ECA; CLT.

\section{Introdução}

"O homem é um ser que trabalha e produz o mundo e a si mesmo". Em poucas linhas de sua didática obra, Maria Lúcia de Arruda Aranha (2002, p. 5) descreve o trabalho como uma ação transformadora que altera a percepção, o pensar e o sentir do homem e 0 completa.

Contudo, não é essa a visão que predominou ao longo da história. Na Grécia e Roma antigas, por exemplo, sabe-se que o trabalho era considerado uma atividade indigna e executada pelos escravos. A própria etimologia da palavra trabalho, que vem do vocábulo latino tripalium (é um instrumento romano de tortura, uma espécie de tripé formado por três estacas cravadas no chão, no qual eram supliciados os escravos), reforça esse caráter negativo (WIKIPÉDIA, 2008).

0 advento da Revolução Industrial e a concentração de poder acentuam a exploração do trabalho manual e coloca crianças, que em épocas remotas já trabalhavam em corporações de ofícios, para manejar ou vigiar máquinas por jornadas de 14 a 16 horas em troca de salários irrisórios.

\footnotetext{
${ }^{1}$ Estudante do 40 ano de Direito da Universidade Estadual de Londrina.

${ }^{2}$ Advogada. Docente junto ao Departamento de Direito Público da UEL.
} 
A esse respeito, expõe Alice Monteiro de Barros (2006, p. 517) que "a dificuldade econômica tem sido a principal responsável pela exploração de que são vítimas os menores, desde a primeira infância e nas mais variadas épocas da humanidade".

É no meio desses dois extremos, o do ideal e o do real, que, seguindo uma tendência internacional, surge o Estatuto da Criança e do Adolescente, especificando matéria elencada, sobretudo, no art. 227 da Constituição da República Federativa do Brasil de $1998^{3}$.

0 tratamento legal, longe de tentar desestimular, inibir ou até proibir o trabalho do adolescente, busca tutelá-lo conforme reza o princípio da proteção integral, a fim de possibilitar a educação, garantir mínimas condições de trabalho e evitar abusos que possam trazer danos ao desenvolvimento, distúrbios, anomalias e uma infância infeliz.

A tutela especial, como expõe Sérgio Pinto Martins (2006, p. 517), envolve questões de ordem cultural, moral, fisiológica e de segurança.

Justifica-se o fundamento cultural, pois o menor deve poder estudar e receber instrução. No que diz respeito ao aspecto moral, deve haver uma proibição no sentido de o menor não trabalhar em locais que Ihe prejudiquem a moralidade. No atinente ao aspecto fisiológico, o menor não deve trabalhar em locais insalubres, perigosos, penosos ou a noite, para que possa ter um desenvolvimento físico normal. Por último, o menor, assim como qualquer trabalhador, deve ser resguardado com normas de proteção que evitem os acidentes de trabalho, que podem prejudicar sua formação normal.

Outro ponto que merece destaque diz respeito à íntima inter-relação do assunto trabalhado Estatuto da Criança e Adolescente com o capítulo IV (Da proteção do trabalho do menor - art. 402 a 441) do título III (Das Normas Especiais de Tutela) da CLT, Consolidação das Leis Trabalhistas, a ponto de alguns dispositivos se completarem ou até se repetirem, 0 que pode tornar duvidosa a efetivação de alguns pontos da lei, já que o assunto, apesar de tratado pela CLT encontra disparidades com a realidade.

A vida não dá a oportunidade de escolha ao menor trabalhador de estudar em detrimento de laborar, pois não há como estudar de estômago vazio ou doente. A má distribuição de renda do país, que é uma das piores do planeta, somada a

\footnotetext{
3 “É dever da família, da sociedade e do Estado assegurar à criança e ao adolescente, com absoluta prioridade, o direito à vida, à saúde, à alimentação, à educação, ao lazer, à profissionalização, à cultura, à dignidade, ao respeito, à liberdade e à convivência familiar e comunitária, além de colocá-los a salvo de toda forma de negligência, discriminação, exploração, violência, crueldade e opressão" (Art. 227, CF).
} 


\section{Do direito à profissionalização e da proteção no trabalho ao adolescente à luz do estatuto da criança e do adolescente}

existência de salários cada vez mais baixos, custo de vida cada vez mais alto e altos índices de desemprego são as maiores causas da inserção da criança e do adolescente no mercado de trabalho. (TEIXEIRA, 2003).

Contudo, a sociologia do Direito de Felipe Augusto de Miranda Rosa (1970, p. 53) nos ensina que:

A norma jurídica, portanto, é um resultado da realidade social. Ela emana da sociedade, por seus instrumentos e instituições destinados a formular o Direito, refletindo 0 que a sociedade tem como objetivos, bem como suas crenças e valorações, o complexo de seus conceitos éticos e finalísticos.

É nesse sentido que atua o Estatuto da Criança e do Adolescente, como uma norma que ao mesmo tempo em que reflete a realidade social, projeta para o futuro, por possuir função educadora e transformadora, ao tratar de questões referentes à idade, direitos, deveres e proibições, a aprendizagem e o trabalho educativo como passaremos a expor.

\section{A idade e o trabalho}

0 primeiro ato para a proteção dos menores ocorreu na Inglaterra, com o Moral and Health Act, expedido por Robert Pell em 1802, com o lema "salvemos os menores" que culminou com a redução da jornada de trabalho para 12 horas, conforme lembra Amauri Mascaro Nascimento (2001, p. 520).

No âmbito interno, as Constituições de 1824 e 1891 foram omissas em relação ao trabalho do menor de idade. Além disso, como expõe Alice Monteiro de Barros (2006, p. 520), apesar de o Brasil ter sido o primeiro país da América Latina a editar normas de proteção ao menor, em 1891, com decreto 1313, foi apenas com o Código de Menores de 1927, decreto no 17.943-A, conhecido como lei de Mello Mattos, que a matéria começou a ganhar força. ${ }^{4}$

O assunto passou a ser tratado constitucionalmente a partir de 1934. A Constituição de 1946 chegou a prever idade mínima de 14 anos para o trabalho, a Constituição de 1967 rebaixou para 12 anos, mas a atual Carta Maior re-elevou para 14 anos a idade mínima para o trabalho e proclamou uma série de direitos.

\footnotetext{
${ }^{4} 0$ revogado código estabelecia, em vinte e quatro artigos, condições, limitações e multas a questões atinentes ao trabalho do menor, como a proibição do trabalho a menores de 12 anos (art. 101).
} 
Contudo, a Emenda Constitucional № 20 de 15/12/1998 fixou limite mínimo de 16 anos para o trabalho do menor de idade, admitindo sua contratação como aprendiz a partir dos 14 anos, derrogando 0 art. 60 do Estatuto da Criança e do Adolescente (ECA) ${ }^{5}$.

A respeito dessa inovação, expõe Sergio Pinto M artins (2006, p. 340) que "a nova determinação constitucional mostra a tese de que o lugar do menor é na escola e não no trabalho. Entretanto, é preferível o menor trabalhar a praticar furtos e roubos nas ruas ou usar drogas".

Ainda sobre 0 assunto, escreve Roberto João Elias (2004 p. 57):

Se, por um lado, o estatuído evita que os menores ingressem no campo de trabalho sem a devida maturação, o que po de prejudicar o seu desenvolvimento, por outro, pode representar um empecilho aos que, para auxiliar no orçamento familiar, têm necessidade de trabalhar desde cedo.

Contudo, a efetividade da lei é relativa, haja vista a alta taxa de trabalho infantil. A Pesquisa Nacional por Amostra e Domicílio (PNAD), do Instituto Brasileiro de Geografia e Estatística (IBGE), realizada em 2006, verificou que no Brasil, existem cerca de 5,1 milhões de crianças e adolescentes trabalhadores, sendo que 1,4 milhões possuem de 5 a 13 anos de idade (Instituto Brasileiro de Geografia e Estatísitica, 2006).

0 trabalho infantil é resultado de uma série de fatos, como bem lembra o professor Oris de Oliveira (CURY, 2006, p. 211), e sua eliminação é um processo gradativo. Ele complementa a presente idéia:

A maior lição que hoje se tira no embate da eliminação do trabalho infantil é que ele só se erradica preenchendo o "não proibitivo legal" com alternativas positivas: programas de educação, de lazer, de emprego e renda para os pais, de venda mínima - todos eles acoplados à freqüência a escola.

O parágrafo único do art. 402 da Consolidação das Leis Trabalhistas (CLT) contempla outra exceção. Trata-se do trabalho em oficinas em que trabalhem pessoas da família do menor e esteja esta, sob direção do pai, mãe ou tutor. Observa-se neste caso que não haverá vínculo de emprego nos casos em que há colaboração entre pessoas para um fim comum.

\footnotetext{
5 "É proibido qualquer trabalho a menores de quatorze anos de idade, salvo na condição de aprendiz" (Art. 60, ECA).
} 


\section{Do direito à profissionalização e da proteção no trabalho ao adolescente à luz do estatuto da criança e do adolescente}

Da mesma forma em relação a participação dos filhos nos afazeres domésticos, pois entende-se que "faz parte de um processo educativo exigir que todos os filhos prestem sua colaboração, sobretudo na atual conjuntura, em que a mulher trabalhar fora do lar, e sobre cujos ombros não podem recair os encargos de uma dupla jornada" (CURY, 2006, p. 210).

Apesar do foco deste artigo ser o trabalho do adolescente a luz do Estatuto da Criança e do Adolescente, é necessário abordar o tratamento segundo outras legislações a fim de se buscar uma ampla abordagem.

\section{0 trabalho segundo a legislação especial}

Uma das principais leis que tratam do assunto é a Consolidação das Leis Trabalhistas (CLT), sobretudo no capítulo dedicado ao trabalho do menor de idade que abrange os art. 402 a 441.

Dentre os muitos dispositivos, o referido capítulo enumera a liberdade de o menor ser contratado, necessitando dos pais apenas no momento da confecção da Carteira de Trabalho e Previdência Social (art. 416) e da quitação final (art. 439); que a jornada de trabalho não pode ter mais de 8 horas semanais (art. 411), independentemente de o menor ser empregado em mais de um estabelecimento (art. 414); que a prorrogação da jornada de trabalho só se prorrogará em regime de compensação (no máximo duas horas por dia) ou por força maior (até quatro horas por dia, desde que não ultrapasse as 44 horas semanais), salvo 0 direito de receber acréscimo de 50\% sobre a hora normal (art. 413) (CLT).

A fiscalização do trabalho do menor de idade, conforme expõe o professor Oris de Oliveira (CURY, 2006, p. 211), cabe ao M inistério do Trabalho, ao M inistério Público, ao Juízo da Infância e Juventude e ao Conselho Tutelar, cada um atuando dentro de sua esfera de competência.

Em análise sobre a fiscalização do menor no contrato de aprendizagem com empresas, escreve Luciana Brancaglione (2007):

Analisamos os órgãos competentes para a fiscalização e o combate da exploração do trabalho do menor e concluímos que o Ministério do Trabalho e Emprego, por meio da atuação dos auditores-fiscais do trabalho, está mais aparelhado para verificar in loco a condição a que se submete o menor no contexto do contrato de aprendizagem celebrado com o micro e pequeno empresário. 
Contudo, é necessário lembrar que o rol é mais extenso, tendo em vista o já frisado art. 227 da Constituição Federal, que enumera a família, a sociedade e o Estado.

Há de se observar ainda que a apreciação das leis que relacionam o assunto não se restringe apenas a legislação trabalhista e que cada modalidade de trabalho recebe um tratamento específico, a saber, o trabalho familiar, o do aluno assistido, do aprendiz, que será tratada em tópico a parte após a abordagem temas genéricos relacionados à proteção do trabalho do adolescente, dentre outros.

\section{Vedações ao trabalho do adolescente}

Todas as vedações da legislação têm como objetivo a proteção integral e se aplicam ao trabalho do menor de idade independente do regime e condições de trabalho em que se encontra.

Nesta linha, ampliando alguns dos dispositivos da Consolidação das Leis Trabalhistas (CLT), o Estatuto da Criança e do Adolescente (ECA), em seu artigo 67, proíbe ao adolescente empregado, aprendiz, em regime familiar de trabalho, aluno de escola técnica, assistido em entidade governamental ou não-governamental o trabalho noturno, realizado entre as vinte e duas horas de um dia e às cinco horas do dia seguinte; perigoso, insalubre ou penoso; realizado em locais prejudiciais à sua formação e ao seu desenvolvimento físico, psíquico, moral e social; realizado em horários e locais que não permitam a freqüência à escola.

Vale lembrar que o presente artigo 67 do ECA vem confirmar o disposto na Constituição Federal, art. 7ํ, XXXIII que já estabelecia a proibição do trabalho noturno, perigoso e insalubre.

Sobre o trabalho noturno, compreende-se a proibição como meio de proteger 0 desenvolvimento físico, já que a garantia do bom sono é essencial para tal.

Perigoso é o trabalho que ameaça a integridade física do adolescente e pode até causar risco de morte, ao colocá-lo em contato com produtos químicos, inflamáveis, equipamentos cortantes e explosivos. A proibição vem amparada no fato de muitas vezes 0 menor de idade não conseguir ter a devida atenção e cuidado em tarefas que exigem essa maior diligência.

Por insalubre, entende-se o que traz risco a saúde. São consideradas atividades ou operações insalubres aquelas que, por sua natureza, condições ou métodos de trabalho, 


\title{
Do direito à profissionalização e da proteção no trabalho ao adolescente à luz do estatuto da criança e do adolescente
}

exponham os empregados a agentes nocivos à saúde, acima dos limites de tolerância fixados em razão da natureza e da intensidade do agente e do tempo de exposição aos seus efeitos nocivos à saúde (Portal Sebrae-SP, 2008). Essa proteção visa garantir o desenvolvimento sadio do menor, haja vista que o corpo deste é mais suscetível a certos elementos químicos, por exemplo, do que o dos adultos.

A portaria SIT/DSST no 20 de 13/09/2001 expõe um quadro com 81 atividades consideradas perigosas ou insalubres revistas bienalmente conforme determinado pelo art. 441 da CLT.

Já o trabalho penoso é "o que causa maior desgaste físico ou psíquico, exigindo, por exemplo, uso de força muscular não proporcional ao desenvolvimento físico ou que possa comprometê-lo" (CURY, 2006, p. 234). Esta vedação pode ser observada, por exemplo, na proibição de carregar pesos superiores a 20 e 25 quilos, conforme se trate de trabalho contínuo ou eventual, respectivamente (Art. 405, §50 e art. 390 da CLT).

A lei também proíbe trabalho que possa prejudicar o desenvolvimento físico, psíquico, moral ou social, como o vinculado ao jogo, sexo, violência ou drogas, ou que, real ou potencialmente, venha a privar o adolescente da família e de sua comunidade, por exemplo, tornando o trabalho socialmente prejudicial.

Como exposto no inciso IV do art. 68 do ECA, o trabalho deverá ser realizado em horários e locais que permitam a freqüência à escola. A esse respeito, bem escreve Oris de Oliveira (CURY, 2006, p. 235):

\begin{abstract}
As normas jurídicas garantem não somente a compatibilidade escola-trabalho, mas inequivocadamente dão preferência à escolaridade sobre 0 trabalho. Esta compatibilidade deve concretizar-se em duração de jornada que efetivamente permita a freqüência à escola. Não basta, também, que haja um tempo de deslocamento físico entre os estabelecimentos empresarial e escolar. 0 espírito da lei é no sentido de que o trabalho não prejudique o acesso (ou regresso) à escola, a permanência e o sucesso.
\end{abstract}

A realidade brasileira nos mostra que há muito a se caminhar para alcançar a proteção aqui referida. As dificuldades continuam e até aumentam quando se fala em trabalho do adolescente portador de deficiência. Contudo, é importante abordar o assunto haja vista a existência de tratamento legal. 


\section{0 trabalho do adolescente portador de deficiência}

A proteção ao trabalho do adolescente é elencada no art. 66 do ECA e decorre do art. $227, \S 1^{\circ}$, II, da CF, que preceitua a criação de programas de prevenção e atendimento especializado para os portadores de deficiência física, sensorial ou mental, bem como de integração do adolescente portador de deficiência mediante treinamento para o trabalho e a convivência, e a facilitação do acesso aos bens e serviços coletivos, com a eliminação de preconceitos e obstáculos arquitetônicos.

Em relação à proteção especial, percebe-se que surge como meio para promover a igualdade material ao tratar cada um segundo a sua necessidade.

0 trabalho protegido há de ser entendido não como um privilégio ao adolescente portador de deficiência, mas como uma forma de assegurar-lhe aquilo que aos outros é cedido. Assim sendo, a proteção representa a forma de se alcançar um equilíbrio. Não há, no caso, nenhuma ofensa aos princípios constitucionais, mormente aos estabelecidos no art. 50 da Carta Magna (ELIAS, 2004, p. 62).

As disposições usadas para garantir esse equilíbrio são chamadas de ações afirmativas (REIS, 2004) ${ }^{6}$.

A sua finalidade é procurar integrar 0 adolescente portador de deficiência, mediante 0 aproveitamento de sua capacidade residual, na comunidade, pelo exercício de uma atividade que Ihe garanta um meio de sustentação e também um meio de realização e superação da sua própria deficiência, evitando-se sua marginalização (CURY, 2006, p. 225).

A proteção significa também que, dependendo do grau de deficiência, o trabalho será regulado para que o adolescente possa desempenhar o trabalho da melhor maneira possível e sem agravar sua deficiência.

Devem constar da legislação as diretrizes norteadoras do preparo dos portadores de deficiência para o mercado, mediante um programa educacional que os torne aptos para o exercício de uma atividade. Este preparo vai requerer, ainda, a formação de técnicos e professores especializados para a formação profissional do adolescente portador de deficiência. E exigir uma coordenação de esforços que vão desde os cuidados com a saúde, a avaliação da capacidade residual do deficiente e

\footnotetext{
${ }^{6}$ Conforme definição do Senador Abdias Nascimento em discurso no Senado Federal 13/05/1998, a ação afirmativa consiste em "um conjunto de instrumentos utilizado para promover a igual dade de oportunidades no emprego, na educação, no acesso à moradia, e no mundo dos negócios, onde se busca, através da prevenção, alcançar uma sociedade inclusiva, aberta à participação igualitária de todos os cidadãos.
} 


\section{Do direito à profissionalização e da proteção no trabalho ao adolescente à luz do estatuto da \\ criança e do adolescente}

as possibilidades de seu aproveitamento, de criação de centros ou escolas de treinamento, até o cadastramento de firmas, empresas ou indústrias capacitadas para absorver esta mão-de-obra, seja na área pública ou privada (CURY, 2006, p. 229).

Diante da abordagem dessas questões genéricas sobre o trabalho da criança e do adolescente com a realizada ressalva para o trabalho do portador de deficiência, é indispensável tratar da aprendizagem, um instituto que tutela a formação profissional de adolescentes em determinada faixa etária.

\section{A aprendizagem}

A aprendizagem é tratada pelo art. 62 do ECA como a formação técnico-profissional ministrada segundo as diretrizes e bases da legislação de educação em vigor.

A lei de Diretrizes e Bases da Educação Nacional (LDB), de no 9394 de 1996, concebe a educação como um processo formativo que ocorre nos mais diversos segmentos sociais (família, escola, comunidade, etc) e que tem por finalidade o pleno desenvolvimento do educando, seu preparo para o exercício da cidadania e sua qualificação para o trabalho (Art. 10 e $2 \stackrel{0}{\text { da }}(D B)$.

Verifica-se logo de início a existência de uma íntima relação entre educação e trabalho, que, em relação ao adolescente, transparece no artigo 36-A a D da LDB, o qual expõe sobre a possibilidade da educação profissional técnica no nível médio, durante ou subseqüente a sua realização.

No que diz respeito à formação técnico-profissional, percebe-se que há a preocupação em formar concomitantemente o cidadão e o profissional, e não apenas adestrar alguém para ocupar um lugar no processo de produção, como expõe Alice M onteiro de Barros (2006, p. 537).

Nessa mesma linha, o professor Oris de Oliveira (CURY, 2006, p. 214) interpreta a formação técnico-profissional como um ensino geral que contribui para o desenvolvimento da personalidade e do caráter, e completa:

Ensino técnico e profissional é um termo utilizado em sentido lato para designar o processo educativo quando este implica, além de uma formação geral, estudos de caráter técnico e a aquisição de conhecimentos e aptidões práticas relativas ao exercício de curtas profissões em diversos setores da vida econômica e social. 
A aprendizagem é, portanto, mais do que um simples preparo para atender as necessidades do mercado de trabalho. É uma importante etapa do processo educacional que se conceitua como

[...] um ensino com alternância (conjugando-se teoria e prática), metódico (implicando operação ou módulos ordenados em conformidade com um programa em que se passa do menos complexo para o mais complexo), sob orientação de um responsável (pessoa física ou jurídica) em ambiente adequado (condições objetivas: pessoal, docente, aparelhagem). (CURY, 2006, p. 215).

Sobre o assunto, a CLT traz uma seção dentro do capítulo da proteção do trabalho do menor de idade que trata do assunto.

Art. 428. Contrato de aprendizagem é o contrato de trabalho especial, ajustado por escrito e por prazo determinado, em que o empregador se compromete a assegurar ao maior de 14 (quatorze) e menor de 24 (vinte e quatro) anos inscrito em programa de aprendizagem formação técnico-profissional metódica, compatível com o seu desenvolvimento físico, moral e psicológico, e o aprendiz, a executar com zelo e diligência as tarefas necessárias a essa formação. ${ }^{7}$

O contrato de aprendizagem é uma exceção à regra da proibição do trabalho aos menores de 16 anos e tem como requisito essencial, o preenchimento de formalidades expressas em lei.

A validade do contrato de aprendizagem à luz do $\S 10$ do art. 428 da CLT, acrescentando pela lei 10.097 , de 2000, pressupõe anotação na CTPS, matrícula e freqüência do aprendiz na escola, caso não haja concluído o ensino fundamental, além de inscrição em programa de aprendizagem desenvolvido sob orientação de entidade qualificada em formação técnico-profissional metódica (BARROS, 2006, p. 538).

Além disso, a CLT traz outros dispositivos relevantes, como a limitação em seis horas da jornada de trabalho dos aprendizes, salvo se este já houver terminado o ensino fundamental (art. 432), duração máxima de dois anos para o contrato de aprendizagem (art. 428), dentre outros que serão abordados. As empresas não poderão ter menos de $5 \%$ e mais

\footnotetext{
${ }^{7} 0$ programa de aprendizagem, de acordo com os arts. 428 e 430 da CLT serão desenvolvidos por um dos Serviços Nacionais de Aprendizagem (SENAI, SENAC, SENAR, SENAT e SESCOOP), ou, na falta dessas instituições, em Escolas Técnicas de educação, entidades sem fins lucrativos ou, como dispõe 0 art. 427 da referida lei, na própria empresa.
} 


\section{Do direito à profissionalização e da proteção no trabalho ao adolescente à luz do estatuto da criança e do adolescente}

que $15 \%$ de aprendizes no seu estabelecimento (art. 429). As microempresas e empresas de pequeno porte foram dispensadas do cumprimento desta regra pela lei 9841/99 (CARRION, 2004, p. 31).

Ainda sobre 0 assunto, a Lei Complementar de № 123/06 instituiu em seu art. 51, inciso III que as microempresas e empresas de pequeno porte de empregar estão desobrigadas a matricular seus aprendizes nos cursos dos Serviços Nacionais de Aprendizagem.

Assim, entendemos que 0 inciso III do artigo 51 da Lei Complementar 123/06 é inconstitucional e eventual interpretação gramatical pode levar à errônea conclusão de que os microempresários e os empresários de pequeno porte podem contratar o menor entre 14 anos e 16 anos incompletos como aprendiz e dele exigir apenas a prática da atividade desenvolvida. Ou seja, receamos que 0 contrato de aprendizagem encubra uma verdadeira relação de emprego, por não vir acompanhado de convênio com instituição de formação teórico-profissional e que, com isso, o empresariado se olvide do verdadeiro objetivo do contrato, que é 0 de proporcionar ao menor oportunidade para desenvolvimento educacional, emocional e profissional e formar cidadãos (BRANCAGLIONE, 2007).

Em outra análise da questão, Sergio Pinto Martins (2006, p. 358) aponta outro problema que pode surgir.

Somadas a porcentagem de aprendizes e a de pessoas reabilitadas ou portadoras de deficiência, a empresa tem grande potencial a destinar para pessoas específicas. Num contexto de globalização, tais percentuais podem diminuir as condições de concorrência da empresa no mercado.

O decreto no 5598 de 2005 amplia o tratamento dado ao tema ao discorrer sobre as entidades qualificadas em formação técnico-profissional metódica (art. 8ํ), a respeito da contratação de aprendiz pela Administração Pública (art. 16), atividades teóricas e práticas (art. 22 e 23) e efeitos dos instrumentos coletivos de trabalho (art. 26).

Como já relatado anteriormente, a aprendizagem ou formação técnico-profissional, consiste na realização de atividade que possibilite o crescimento profissional cumulado com o desenvolvimento físico, mental e psicológico.

Para atingir esse objetivo, a legislação brasileira elenca pressupostos a serem obedecidos, a saber: a garantia de acesso e freqüência obrigatória ao ensino regular; compatibilidade com o desenvolvimento e horário especial para o exercício das atividades 
(art. 63, ECA). A esse respeito escreve João Roberto Elias (2004, p. 60) que "dentro do princípio da proteção integral, não se pode ignorar nenhum aspecto que possa servir de obstáculo ao pleno desenvolvimento do menor. Assim sendo, a primeira preocupação é com a freqüência ao ensino regular".

Na mesma linha de raciocínio, coloca Oris de Oliveira (CURY, 2006, p. 217):

Sendo a aprendizagem um processo educacional, havia um contra-senso se ela se fizesse à margem da escolaridade, prejudicando-a. 0 mínimo de conhecimentos 'teóricos' (desenho, leitura de tabelas, matemática aplicada) que a aprendizagem exige só se obtém com uma escolaridade regular ou complementar profissional à complexidade do que é concretamente objeto da aprendizagem.

Além disso, a atividade deve ser compatível com o desenvolvimento, pois o aprendizado não pode se tornar uma atividade danosa, sob pena de se descaracterizar como tal. Por isso a existência de vedações que serão abordadas em outro momento.

A lei também ressalva a questão do horário que deve ser dividido por períodos de maior ou menor prática ou teoria, de acordo com o programado.

A CLT enuncia a necessidade de conjugar estudo e trabalho no capítulo dedicado ao trabalho do menor. 0 parágrafo único do art. 403 dessa lei expõe que o trabalho do menor não poderá ser realizado em horários e locais que não permitam à freqüência a escola.

0 Estatuto da Criança e do Adolescente dispõe em seu artigo 64 que ao adolescente até quatorze anos de idade é assegurada bolsa aprendizagem. A doutrina constata certo contra-senso neste dispositivo.

Está em dissonância com a nova dicção constitucional introduzida pela Emenda de ํำ20, de 15/12/98 [...] A aprendizagem regular, formal, agora, somente poderá começar aos 14 (quatorze) anos de idade. Assim 0 artigo 64 do ECA resta sem eficácia (ELIAS, 2004, p. 73).

Com os mesmos pensamentos escreve Oris de Oliveira (CURY, 2006, p. 219) que "o atual texto constitucional do referido inciso XXXIII (do art. 70) fixa a idade mínima de aprendizagem em 14 anos. Conseqüentemente, em uma relação de emprego 0 adolescente não pode trabalhar na condição de aprendiz".

Sobre a bolsa de aprendizagem, 0 art. 428, §20 da CLT dispõe que "ao menor aprendiz, salvo condição mais favorável, será garantido o salário mínimo hora", ao contrário 


\section{Do direito à profissionalização e da proteção no trabalho ao adolescente à luz do estatuto da \\ criança e do adolescente}

do revogado art. 80 da CLT, que previa ao menor aprendiz salário nunca inferior a meio salário mínimo durante a primeira metade da duração máxima do aprendizado e de dois terços durante a segunda metade do contrato.

0 referido dispositivo legal já havia sido revogado pela Constituição de 1988, que determina, no inciso XXX do artigo 7ำ, que não pode existir discriminação de salário quanto a idade. Era o que fazia a CLT, ao determinar salário nunca inferior ao mínimo para 0 aprendiz. Foi revogado expressamente 0 art. 80 da CLT pela Lei $10.097 / 2000$ (MARTINS, 2006, p. 357).

0 ECA, no artigo art. 65, assegura os direitos trabalhistas e previdenciários ao adolescente aprendiz, em decorrência do art. 227, §3ำ, inciso II da Constituição Federal que postula que o direito da proteção especial abrangerá a garantia do acesso do trabalhador adolescente à escola.

Sobre 0 assunto, escreve Romeu Tadeu M arques da Fonseca (CURY, 2006, p. 225):

0 aprendiz que se submeter, portanto, a processos de aprendizagem empresarial será protegido com direitos trabalhistas e previdenciários. Rompe-se, deste modo, definitivamente, com o chamado trabalho assistencial que perdurou no Brasil por décadas. Não mais se admite a idéia de que qualquer trabalho é preferível ao abandono das ruas.

João Roberto Elias (2004, p. 61) ressalta, dentre os direitos trabalhistas garantidos no art. 70 da Constituição, o seguro desemprego, o salário mínimo, gozo de férias anuais remuneradas com um terço a mais que o salário normal, e dentre os previdenciários, que a Constituição acolhe no art. 201 e 202, os benefícios por enferminidade, inclusive os oriundos de acidente de trabalho, além de outros constantes em normas infraconstitucionais.

Dentre estas, destaca-se o decreto 5598/05, que regulamenta a contratação de aprendizes e dispõe sobre o fundo de garantia por tempo de serviço (art. 24), férias (art. 25), vale-transporte (art. 27), dentre outras coisas.

Contudo, tendo em vista a nova doutrina que surge com o ECA que eleva a criança e o adolescente à condição de cidadãos, há de se ressaltar que ao mesmo tempo em que a legislação tutela sua profissionalização, impõe ao adolescente o dever comportar-se adequadamente no ambiente de trabalho, razão pela qual o contrato de aprendizagem poderá se extinguir mediante constatação de desempenho insuficiente ou inadaptação do 
aprendiz, falta disciplinar grave ou ausência injustificada à escola que implique perda do ano letivo (Art. 433, I, II e III da CLT).

Cumpre, antes das últimas considerações, abordar uma última modalidade de trabalho introduzida pelo ECA e pouco conhecida.

\section{0 trabalho educativo}

Conforme preceitua 0 art. 68 do ECA, 0 trabalho educativo consiste em atividade, sob responsabilidade de entidade governamental ou não-governamental sem fins lucrativos, que deverá assegurar ao adolescente que dele participe condições de capacitação para 0 exercício de atividade regular remunerada de modo que as exigências pedagógicas relativas ao desenvolvimento pessoal e social do educando prevaleçam sobre 0 aspecto produtivo.

Ao lado do trabalho do menor de idade e do trabalho do aprendiz, surge no presente artigo a figura do trabalho educativo, não tratado pela CLT, resultado da articulação da educação e do trabalho e que proporciona ao menor de idade, que poderia estar nas ruas, crescimento pessoal e social,

não uma atividade laborativa qualquer, mas que se insere como integrante de projeto pedagógico que vise ao desenvolvimento pessoal e social do educando. Portanto o ritmo, o desenrolar das atividades, deverá ser ditado, sob pena de inversão de meios e fins, por um programa educacional estabelecido (CURY, 2006, p. 236).

Há de se entender que além do aspecto educativo, este tipo de trabalho vem a proporcionar ensinamentos que o prepare futuramente para o mercado de trabalho. Mas nem por isso, há de se deixar de lado a remuneração, já que a ausência desta pode significar até um enriquecimento ilícito (Art. 68, §2ํ do ECA). "A questão da remuneração, nessa fase, deve ser secundária, sobressaindo o caráter educativo. Porém, é relevante que ela exista, com respeito ao princípio de que a todo trabalho deve corresponder uma contraprestação pecuniária" (ELIAS, 2004, p. 64).

Contudo, como bem ressalta Antônio Carlos Gomes da Costa (CURY, 2006, p. 225), há certa dificuldade em delimitar até que ponto vai o trabalho educativo, da mesma forma em que se pode encontrar dificuldades para delimitar o trabalho penoso, como fora visto anteriormente. 
A dificuldade, ou, melhor dizendo, os aspectos mais desafiadores desta questão, se encontra na definição prática do limite entre o trabalho simplesmente produtivo e 0 trabalho educativo. Entendo que, neste ponto, dois aspectos fundamentais devem ser tomados em conta: o primeiro diz respeito ao número de horas de atividades orientadas voltadas para a produção e aquelas voltadas para a formação do educando; o segundo, à natureza, ou seja, ao caráter das atividades laborais realizadas em termos de ritmo e de estruturação de modo a permitir uma real aprendizagem por parte do trabalhador educando, ou seja, as atividades laborais devem ajudar e não prejudicar o processo aprendizagem/ensino.

\section{Conclusão}

Diante do exposto, é imperioso tentar compreender, antes de qualquer outra coisa, a essência da proteção ao trabalho do adolescente.

Não é difícil deparar-se com opiniões de indivíduos que, antes de uma tentativa de compreensão dos institutos legais aqui trabalhados, refutam a discussão de qualquer tema relacionado à proteção da criança e do adolescente, graças, principalmente, a fatos que envolvem a prática de ato infracional, sua repercussão e interpretação distorcida.

Em um passado não muito distante, alguns indivíduos lutavam pela aprovação de projetos que proibiam trabalho a menores de 10 anos, já que era possível encontrar crianças de 8 anos em fábricas insalubres no Brasil (SÜSSEKIND, 2002, p. 986).

Hoje, observa-se certo progresso das leis nesse sentido, mas uma realidade ainda alarmante: milhões de crianças e adolescentes trabalhando na informalidade, em regime de semi-escravidão e muitos dos quais sem receber remuneração.

É, sobretudo, contra essa realidade que a lei existe. 0 ECA e as demais leis, não buscam impedir o trabalho, mas sim sua exploração.

Por fim, busca-se, tutelar o trabalho do adolescente com vista a respeitar sua condição de pessoa em desenvolvimento e proporcionar sua capacitação profissional. A educação é um processo que se desenvolve não só na escola, mas também na família, na comunidade, na igreja e no trabalho, que é de suma importância para a formação do indivíduo.

\section{Referências}


ARANHA, M aria Lúcia de A. M ARTINS, M aria Helena P. Filosofando: introdução à filosofia. 2. ed. rev. e atual. São Paulo: M oderna, 2002.

BARROS, Alice M onteiro de. Curso de Direito do Trabalho. 2. ed. rev. e ampl. São Paulo: LTr, 2006

BRANCAGLIONE, Luciana Helena. Sobre os reflexos da Lei Complementar no 123/2006 no contrato de aprendizagem. Jus Navigandi, Teresina, ano 11, n. 1512, 22 ago. 2007.

Disponível em: ঝttp://jus2.uol.com.br/doutrina/texto.asp?id=10298 >. Acesso em: 25 fev. 2008.

BRASIL. Presidência da República. Constituição da República Federativa do Brasil de 1988. Disponível em: ঝtttp://www.planalto.gov.br/ccivil_03/constituicao/constituiçao.htm>. Acesso em: 10 nov. 2008.

. Presidência da República. Consolidação das Leis do Trabalho. Disponível em: http://www.planalto.gov.br/ccivil/Decreto-Lei/Del5452.htm>. Acesso em 10 de Nov. de 2008.

. Presidência da República. Decreto 5.598. Disponível em: বhttp://www.planalto.gov.br/ccivil_03/_Ato2004-2006/2005/Decreto/D5598.htm>. Acesso em: 10 nov. 2008.

. Presidência da República. Estatuto da Criança e do Adolescente. Disponível em: বhttp://www.planalto.gov.br/ccivil/LEIS/L8069.htm>. Acesso em: 10 nov. 2008.

CARRION, Valentin. Comentários à Consolidação das Leis do Trabalho. 29. ed. São Paulo: Saraiva, 2004.

CURY, M unir. Estatuto da Criança e do Adolescente Comentado: comentários jurídicos e sociais. 8. ed. São Paulo: Malheiros, 2006.

ELIAS, João Roberto. Comentários ao Estatuto da Criança e do Adolescente. 2. ed. São Paulo: Saraiva, 2004.

Instituto Brasileiro de Geografia e Estatística. Suplemento Trabalho Infantil - PNAD 2006.

Disponível em:

বttp://www.ibge.gov.br/home/presidencia/noticias/noticia_impressao.php?id_noticia=111 7>. Acesso em: 20 out. 2008.

M ARTINS, Sergio Pinto. Comentários à CLT. 10. ed. São Paulo: Atlas, 2006. NASCIM ENTO, Amauri M ascaro. Curso de Direito do Trabalho. 17. ed. São Paulo: Saraiva, 2001. 
PORTAL Sebrae-SP. O que é Insalubridade? Disponível em: বhttp://www.sp.sebrae.com.br/faq/recursos_humanos/legislacao/insalubridade>. Acesso em: 31 ago. 2008.

SOUZA, Ismael Francisco de. 0 trabalho precoce no Brasil. Jus Navigandi, Teresina, v. 9, n. 732, 7 jul. 2005. Disponível em: <http://jus2.uol.com.br/doutrina/texto. asp?id=6983>. Acesso em: 22 fev. 2008.

REIS, Cristiane de Souza; SOUSA, Carlo Arruda. Breve análise sobre a ação afirmativa. Jus Navigandi, Teresina, v. 9, n. 528, 17 dez. 2004. Disponível em:

বhttp://jus2.uol.com.br/doutrina/texto. asp?id=6050>. Acesso em: 24 fev. 2008.

ROSA, Felippe Augusto de Miranda. Sociologia do Direito: 0 fenômeno Jurídico como Fato Social. Rio de Janeiro: Zahar editor, 1970.

SILVA, Jose Afonso da. Curso de Direito Constitucional Positivo. 27. ed. rev. e atual. São Paulo: Malheiros, 2006.

SÜSSEKIND, Arnaldo et al. Instituições de Direito do Trabalho. 20. ed. São Paulo: LTr, 2002. v. 2.

TEIXEIRA, Wendel de Brito Lemos. A discrepância entre a idade mínima laboral e a realidade brasileira. Jus Navigandi, Teresina, v. 7, n. 62, fev. 2003. Disponível em: বhttp://jus2.uol.com.br/doutrina/texto.asp?id=3710>. Acesso em: 26 fev. 2008.

WIKIPÉDIA: a enciclopédia livre. Tripalium. Disponível em: 〈http://pt.wikipedia.org/wiki/Tripalium>. Acesso em: 21 fev. 2008. 